KLEINE TEXTE FÜR VORLESUNGEN UND ÜBUNGEN HERAUSGEGEBEN VON HANS LIETZMANN

\title{
DIE LINDISCHE TEMPELCHRONIK
}

NEU BEARBEITET

VON

CHR. BLINKENBERG

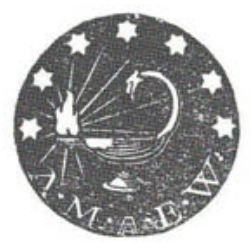

BONN

A. MARCUS UND E. WEBER'S VERLAG

I 9 I 5 